\title{
Notions of Impurity and their operations in the society of early India: Some Reflections based on the Laws of Manu
}

\author{
Aparajita Bhattacharya \\ Assistant Professor, Department of History, Hindu College, University of Delhi, India
}

\section{Introduction:}

The notions of impurity can be conceptualized in relation to the concept of purity .It is quite difficult to arrive at an unanimous notion of purity because of the multidimensionality of its application and differential context and culture specific meaning of the term. Sociologists and anthropologists conducted their studies in this field on the basis of the existential and experiential manifestations of the operation of the concept in a particular society or community. The job a historian is much more complex.

Apart from the socio-economic level the concept of impurity operates in a psychological plain which is at the same time individual and social in their operation. The possibility of socially structured idea of impurity and the individual perception of impurity can be contradictory . While viewing the notion of impurity it is important to distinguish between these two currents. In this paper I want to trace the various notions of impurity as structured by the Hindu dharmasastric injunctions of the Manusmriti and try to analyze the validity of these norms in conceptualizing social interaction of people.

\section{The Text and Context}

The Manusmriti, one of the most influential and controversial juridical literature of ancient India contains 2685 verses arranged in twelve books. The code lays down social, moral and ethical precepts relating to social obligations and duties with an emphasis on the representation of life as "a model of and a model for"( Doniger 1991: xvii).It is a text of multiple authorship composed approximately between 200B.C.E and 200 C.E which depicts generations of composers and the codification of fluid traditions. This kind of composite nature is probably responsible for the various contradictory positions taken by it. On the whole the Manusmrti illustrates the process of reconsolidation of an ongoing vibrant system with emphasis of reorientation of yardsticks (Doniger 1991: xxxv). According to Wendy Doniger, "Contradiction is inevitable in a tradition approaching complex human problems while simultaneously adding new, often different approaches to the same objects" (Doniger 1991: ivi). It should be remembered that is a prescriptive text and how far the laws laid down were actually put in to practice adds further complexity to the whole debate of whether it is feasible to attempt a social reconstruction on the basis of such a literature. The text in consideration is not simply a law book but is a combination of legal code and moral exhortation the main thrust of which is to build up a common cultural pool of wisdom.Colonial perception played a crucial role in the exalted status of the text of Manusmrti as it was regarded as the supreme treatise of 'Hindu law' and a window to glance in to the social relations between different groups of the caste hierarchy in Hindu society.

\section{Notions of Purity and Impurity: Some thoughts}

It is to be bear in mind as has been pointed out by Mary Doughlas that the taboo system should be analyzed not essentially as negative but also as a positive effort to organize the social environment, a creative endeavour to construct a unity of experience. This works on two levels, experiential and expressive placing a symbolic load on the transgressor (Douglas 1980: 116).The whole mechanism of purity and impurity manipulates through the symbolism of danger concerning ambiguity and nonconformity. This anxiety also operates from a marginal status like that of an unborn child or from transitional position like the junction of adolescence and adulthood or the age of puberty. Formlessness or indefinable is the source of power. Douglas argues, "The whole repertoire of ideas concerning pollution and purification are used to make the gravity of the event and the power of the ritual to remake a man" (Douglas 1980:117). Ritual dying and ritual rebirth are prescribed at particular junctures of human life.

Louis Dumont in his book 'Homo Hierarchus' advocates the role of purity norms being the fundamental logic behind the organization of the caste system in India. Quigley while offering a critique of Dumont gives vent to the notion that hierarchy in Hindu society is structured by the norms of purity and pollution (Quigley 1993:1). Although Quigley has not endorsed the view of Dumont that caste hierarchy is a gradational index of ritual purity. Nicholas Dirks challenges the argument of Dumont on the ground of his ethnographic research and holds 
the opinion, "Purity and pollution are not the primary relational coordinates which endow hierarchy with its meaning and substance" (Dirks 1989:61).One of the major strands of Dumont's treatment of the caste system is the exclusion of power as a determining factor of the stratification. According to Dumont the conception of hierarchy is mainly a religious one and has no connection with the power dynamics of society (Dumont 1980:152). Dumont never focuses on the question of dignity and power and the issue of status visa a vie power. Gloria Goodwin Rahejia on the basis of an ethnographic survey of gift giving ritual as practiced in a North Indian village advances the concept of 'ritual centrality. Rahejia shows a central and peripheral configuration of caste as opposed to the Dumont's theory of hierarchical ordering. Patrick Olivelle puts emphasis on the point that the notions on purity and impurity are concerned with individual and not with groups. He holds the opinion that there is no thing as permanent purity, these categories are transitional and hence the purification process for the regaining of the lost status is crucial to the understanding of their implications (Olivelle 1998:190200).Agreeing with the opinion of Mary Douglas Olivelle views the categories of pure and impure as "relational and evaluative concepts" (Olivelle 1998: 211).

It is to be noted that pure and impure are directly concerned with social conformity and impurity results in the case of transgression of that boundary because then it becomes 'matter out of place'. Mary Douglas identified two conditions as the prerequisite for the circulations of such norms viz - a pattern of ordered relations and contradiction within tranquility. In the case of a death of a member of any community the structure of that community gets disturbed which implied an intermediary period of reconstruction in order to regain the former stability. This transitional phase of loosing status and achieving it again is characterized by a period of impurity (Olivelle 1998:212).It is important that impurity occurs within a structure not outside it. To quote Olivelle the whole issue concentrates on the question of 'betwixt and between' which explains that people 'temporarily or permanently in such a marginal zone are not subject to impurity'. So in the case of a death a brahmacarin (student), a dikshita (a person consecrated for a sacrifice), an officiating priest, an ascetic and a male child before Vedic initiation (upanayana) are not subject of these purity regulations.

Women are especially vulnerable to injunctions regarding bodily purity and ritual purity because of her biology. Masculine gaze perceived women as essentially sensual being crippled by her in born sexuality and an inherent combination of weakness and wickedness. Menstruation is seen as a marker of collective sin on the part of women. Moreover her sexual maturity and cyclical fertility all contribute to her potential as a pollutant (Leslie 1996:90-91). In fact the purely biological feature of menstruation carries the double weight of impurity and inauspiciousness. To quote Julia Leslie, “...nor is menstruation condoned as involuntary process .On the contrary it is perceived as the consequence of a sexual violation ...". Leslie draws our attention to the tacit notion of infidelity associated with the menstruation myth - a manifest defiance of the man's accessibility to a woman's body testifying the unreliable nature of them (Leslie 1996:100-101).Until the period of this impurity passed she is not entitled to participate in any ritual ceremony - a device of segregation of women from the main stream of a society. Leslie while dealing with the issue of menstruation in normative discourse points out that the purification ritual prescribed after each cycle reflects on the degree of impurity as the norms are more rigorous for a widow as she has no controlling supervision of a husband over her sexuality. What is interesting is the striking difference between the medical treatises like the Carakasamhita and normative juridical literatures. In the medical discourses the notion of impurity regarding female body and essentially menstruation is conspicuously absent. What is perceived as the most polluting representation of her in born sexuality is also celebrated as the most auspicious symbol of fertility and maternal nourishment - the breast milk (Leslie 1996:92-94).

This association of negativity with the sexuality of women has been described by psycho analyst Sudhir Kakar as the cornerstone of the 'culture's official view' about them. In fact referring to the duties of husband and wife Kakar underlines 'a collective fantasy of the wife' revolving around the "adult women's possible sexual abandon potential infidelity". Kakar tries to explain this eternal male anxiety in terms of what Freud designated as the syndrome of mother - whore dichotomy which perceives separation of sexuality from tenderness or to put it other way, a separation between object of desire and object of adoration. Kakar emphasized the role of the context which portrays her position as good or evil. (Leslie 1990: 17).The connection between impurity and intentionality has been debated by the scholars. While Douglas holds the opinion that this connection is not applicable in comprehending the notion of purity, Olivelle thinks that impurity and immorality are intertwined and interchangeable. There is little doubt on the point that Manusmriti prescribed a hierarchical allocation of punishments to Varnas which has been described by the logic of pollution theory of punishments by the anthropologists and as power theory of punishment by the historians (Glucklich 1982:59)

Michael Aktor's insights in to issue of untouchability should be briefly touched upon here. Aktor is of opinion that untouchability marginalization and can be best understood in terms of power equation in a society .The permanently untouchables like Candalas and temporary untouchability like women both constitute a significant part of society's labour force and hence they are subject to a discourse of dominance devised to appropriate their fruits of labour (Aktor 2012: 21-42). Dumont highlights the idea of occupational dimension 
behind determining the purity position and asserts the fact that any occupation which deals more with organic process is ranked lower than one which deals with them less directly (Dumont 1980:16).Doniger on the other hand identifies a clever tactic in the Dharmasastric emphasis placed on the pursuit of Svadharma or class/ caste specific duties which she described as "a cynical sop thrown to interiorized social groups"(Doniger 1991: XXXVIII).In her introduction to the translation of the Manusmrti she traces in Manu the fact that, "the hierarchically superior prototype is also the generalized archetype - the svadharma of priests is nothing but the general dharma applicable to , until contradicted to all others. And it is precisely in the contradiction that the hierarchical inferiority becomes inevitable" (Doniger 1991: XXXIX).The issue of occupational hierarchy can also be viewed in relation to nonviolence where people who practice it as a part of their duty are more prone to be placed in a lower strata than the people who do not.

Purity and pollution are part of the process of socialization .It directs the individuals to acknowledge the set pattern and boundaries of a society and imposes a defined relation between purity and auspicious. The fear psychosis of the loss of purity and consequently the recovery of that lost status act as the governing mechanism of continuing this structured pattern and further boosts up the notion of caste hierarchy.

\section{Impurity, Hierarchy and the Question of Social Justice}

The members of a higher Varna are considered more vulnerable to pollution comparing to their lower counterparts. The logic behind this is the consideration of the inherent purity of a member of a higher Varna which is essentially greater than the member of a lower Varna who has inherent impurity. In the case of a crime the pollution incurred by the offender is directly proportioned to the caste position of the person and also in the case of a murder the position of the victim. A careful scrutiny of the punishment rules as elaborated in the Manusmrti clearly shows the privileged position of the Brahmans comparing to that of the Kshatriyas and the Vaisyas as they are granted more legal immunities. However Manu never categorically spelt out the logic behind such prescriptions. The operations of the twin principles of 'direct order of reckoning' which sanctions certain concessions to the higher varnas over the lower ones and the 'inverse order of reckoning' which makes the purification process more rigorous for the higher varnas probably explains the working of a stratified society. Scholars like Celestine Bougle try to resolve the factor behind the allocation of punishment by the theory of the punishment depending upon social location rendering its maximum in the case of the offender being of lowest strata and the offended at the highest (Bougle 1971, 122). But this theory of pollution and power fails to solve some questions when applied in the context of Manusmrti .For example in the case of adultery a Brahman and a Vaisya man is supposed to face same sort of punishment for having relation with a Kshatriya woman .On the other hand a Kshatriya man faces more severe punishment than a Vaisya for violating a Brahman woman. So there are apparent contradictions which necessitate a more critical approach in the study of Manusmrti.

Manu said that certain figures should be branded on the forehead of a Brahmin depending on the kind of offence he committed. (Buhler IX: 237).The shaving of head is nominated of a Brahman where others for the same offence even faces death sentence (Buhler VIII 379-380).A Brahmin should not be sentenced to death no matter what ever the offence might be and is allowed to take with him his possessions at the time of banishment from certain territory. Heavy fines and banishment are prescribed for prejudiced Brahmana witness but in the case of rape or adultery the Brahmins are subjected to harsh punishments (Buhler VIII 378) Manu laid emphasis on the performance of penance otherwise the person whose sins have not been expiated will be born with disgraceful inauspicious marks (Buhler IX: 54) .A person who has undergone an ordeal of penance attains Suchi or purity ( Buhler VIII :115) .The sins committed by certain people are considered less detrimental to the society and hence they are pardoned with lesser punishments. The list of these kind of people consists of women ,infants, men with distorted intellect or insanity (unmatta), aged persons, poor(daridras) and people suffering from incurable illness (rogin) (Buhler VIII: 126). What is interesting is that these laws of the criminal procedures are set in a religious framework although they are supposed to be executed by the royal court. Manusmrti mentions that once punished by the king a person goes to heaven and would be purged from all his sins and becomes equal with a person who performed meritorious deeds (Buhler VIII : 318). The category of Mahapataka i.e. committer of mortal sins comprises of the offences of slaying a Brahmin, stilling wealth of a Brahmin, committing adultery with the wife of one's guru etc. The composition of this normative tradition for a substantial period of time which results in adjusting with the changing demands of the situation.

The term Suci figures in the context of pure and Sudhi probably illustrates the process of getting out of impurity The term saucha is used in the case of purification of individuals where as purifications of inanimate objects are referred to as dravyanamsuddhih. Manu prohibits Vedic recitation if the place is not properly purified or the person reciting has not cleansed his soul (Buhler IV: 127). A specific purification process is laid down for a student in order to get initiated in the learning of the Vedas (Buhler IV: 35). The conceptualization of purity has a ethical and moral bearing as well in the virtues like honesty. Differential rituals have been provided for the observation by different social segments, for instance separate regulations for students, householders and 
ascetics (Buhler V: 137).The period of impurity for a mother due to childbirth is called sutaka and the time span of death impurity is asauca (Buhler V: 79). Leftover food referred to as ucchista also constitutes the pollutant category and the persons coming in contact with it also get affected and become impure.

\section{Untouchability and Connection with Impurity:}

The Manusmrti definitely depicts a universalizing tendency with a particular attempt to crystallize the fourfold Varna system.A number of mixed caste unions resulted in the proliferation of mixed groups and hence emergence of new categories. This increase in the numbers of the hybrid groups may be conceptualized in terms of fusion and assimilation quite often captured by the phrase acculturation. Manu was quite explicit that these mixed groups or Varnasamkaras are not strictly a generic category as it applicable to one who relinquishes his obligatory duties. Candalas are considered lowest among the human population and contacts with them is considered to be highly derogatory and polluting. Being born as a Candala was held as the consequence of grave sins like killing a Brahmana in the previous birth. (Buhler X: 55).Manu described the occupations pursued by a number of mixed caste groups. The difference between the Sudras and the Candelas is precisely where the Sudras are granted marginal positions within the caste hierarchy the Candalas are all together excluded from the scheme of caste hierarchy (Jha 1986:12). The Candalas are referred to as antevasins literally meaning one who lives on the fringes of the main settlement. The association of the Candalas with the cremation ground and death impurity plays a crucial factor in placing them at the lowest ebb of the hierarchized society. It would be misconception to view the status of the outcaste groups as a homogeneous entity as there is possibilities of one group enjoining a little better ritual position than the other (Tambiah1973:191-229).

\section{Gender Dimension of Impurity:}

In the Manusmrti women were denied access to upanayana a necessary precondition for the access to the Vedic learning. Marriage has been viewed as equivalent to upanayana for women. As they are deprived of the opportunity of ritual birth as in the case of her twice born male counterparts women are relegated to a inferior position carrying the impurity of being born once in a mere psychical sense and not in a ritual or symbolic sense(BuhlerII :146-148). Manu categorically said that liberation should not be offered to women who have joined a heretical sect, satisfied her lust through many men, caused an abortion, killed her husband or drank liquor (Buhler V: 90). Chastity is the highest rated value. In the situation of a Niyoga where a woman gets involved with a man with the consent of her husband to beget a progeny Manu dictates that the man and woman should behave like father and daughter after the purpose is served. Any defiance in this regard will result in their falling in to the category of Mahapataka or the committer of grave mortal sins (Buhler IX: 63) .An elaborate purification ritual was asked to be performed for coming in to bodily contacts a Candala woman, a woman during menstruation, a lady who has been rendered outcaste for some serious offence and a woman within a certain period from giving birth (Buhler V: 85). But the occurrence of some verses in Manusmrti which illustrates a different angle to this biased view point is indeed puzzling. The statements like the mouth of a woman and the hands of an artisan are always pure or "where women are worshipped there the Gods rejoice' are hard to imagine in the prejudiced scheme of the text. These kinds' paradoxes are indicative of the composite nature of these normative traditions where different trends merged in to a single whole at different junctures but sometimes give a flash of their varied mosaic.

It is interesting to note that both women and Candelas are denied of the right to testify as witness in any dispute. A similarity of position exists between the permanent untouchables like the Candalas and women who shifts in and out of the boundary of purity and pollution throughout their reproductive life. Manu mentioned that only the wife from the same caste i.e. the caste of the husband is entitled to perform ritual functions with her husband. If the husband performs any function with the company of a wife of lower strata he will face the curse of becoming a Candala.

\section{Impurity regarding Death}

When a person dies all the sapindas (direct blood relation) of the deceased become impure and have to observe a period of purification after the completion of which they will again be taken back in to their earlier fold. The duration of the period of impurity depends on whether deceased person was an adult or infant, male or female, whether initiated by the custom of upanayana and also depends on the place of death whether in the house with the proximity of his or her relatives or died away from home. Impurity is directly conditioned on the closeness of the relative with the deceased and the Varna they belong to. Higher the Varna lower the period of impurity. A householder is subjected to carry the burden of higher impurity than a student (brahmacarin), hermit (Vanaprastha status) and a renouncer (Samnyasi). A brahmacarin is not permitted to carry the dead body of even his own caste members except for his parents and teacher and he must not while undertaking the vow (snataka) perform the last rites of any other than his mother (Buhler V: 88, 91). While every individual has to observe a period of impurity in the case of a death of a blood relation, a king has been granted the privilege of 
getting out of this fold of pollution immediately after such death by observing a ritual cleaning. It is obvious that these purity and pollution taboos strengthen the fragmentation of society and leads to the dominance of pure over the impure.

\section{Conclusion:}

The power relation in a society directly influences the categories of purity and pollution. Impurity is always projected as an antithesis of normality. The ambiguity concerning what lies beyond the contours of normal category is also socially constructed .It is invariably involved with the feeling of tension and anxiety arousing from the blocks like 'we' and 'they'. The feeling of otherness and separateness manipulate through the hegemonization of the self as the subject and the other as the object of a discourse.

\section{References}

Aktor, Michael. 'Negotiating Karma: Penance in Classical Indian Law Books' in Ute Husken and Frank Neubert ed, Negotiating Rites, Oxford University Press, New York, 2012.

[1]. Banerjee, N.V. Studies in the Dharmasastra of Manu, MunshiramManoharlal, Delhi, 1980.

[2]. Bhattacharya, Parnasabari. Conceptualization of the Manusmrti, Manohar, New Delhi, 1996.

[3]. Bougle, Celestine. Essays on the Caste System, Cambridge university press, Cambridge1971.

[4]. Buhler, G. (translated) The Laws of Manu, The Sacred Books of the East Series,Vol. 25, General editor F. MaxMuller ,MotilalBanarasidas , Delhi,1988

[5]. Das, R.M. Women in Manu and his Seven Commentators, Kanchana Publications, Varanasi, 1962.

[6]. Derrett, J.D.M. 'Dharmasastra and Juridical Literature' in Jan Gonda Ed History of Indian Literature, Vol 4 Part1, Wiesdiaden, Harrassowitz, 1973.

[7]. Dirks, Nicholas; 'The Original Caste: Power, History and Hierarchy in South Asia' in Contribution to Indian Sociology, vol-3, no 1, Jan-June 1989.pp 59-77.

[8]. Doniger,Windy and Smith,Brian.K (ed) The Laws of Manu, Penguin Books, New Delhi,1991.

[9]. Dumont, Louis. Homo Hierarchus: the Caste system and its Implications, Chicago University Press, Chicago, 1980.

[10]. Douglas, Mary. Purity and Danger: An Analysis of Concepts of Pollution and Taboo, Routledge and Kegan Paul, 1980.

[11]. Glucklich, Ariel. 'Karma and Social Justice in the Criminal Code of Manu' in Contribution to Indian Sociology, Vol 16, No 1, 1982, pp 59-78.

[12]. Hindouancien, Droit. 'Caste and Occupation in Classical India: The Normative Texts' in Contribution to Indian Sociology, Vol 9, No $1,1975$.

[13]. Jha, Vivekananda. 'Stages in the History of Untouchables' in Indian Historical Review, Vol II, 1975, pp 14-31.

[14]. Jha, Vivekananda. 'Candala and the Origin of Untouchability' in Indian Historical Review VolXIII, No 1, 2 1986, pp 1-36.

[15]. Kakar, Sudhir. Intimate Relations, Exploring Indian Sexuality, Penguin Books, Delhi,1990.

[16]. Kane, P.V. History of Dharmasastras, Bhanderkar Oriental Research Institute, Poona Vol I(1990),Vol II Part I and Vol IV,1974.

[17]. Leslie, Julia. ed Roles and Rituals for Hindu Women, MotilalBanarasidas, Delhi, 1992.

[18]. Marglin, F.A; - "Power Purity and Pollution, Aspects of the Caste System Reconsidered" in Contribution to Indian Sociology, Vol 2, No 2, 1977.

[19]. Olivelle, Patrick; - "Caste and Purity: A Study in the Language of the Dharma Literature" in Contribution to Indian Sociology, Vol32, No 2, 1998, pp189-216.

[20]. Quigley, Declan; - The Interpretation of Caste, Clarendon press, Oxford, 1993.

[21]. Raheja, Gloria.Goodwin. The Poison in the Gift: Ritual prostration and the Dominant caste in a North Indian Village, Chicago University Press, Chicago, 1988.

[22]. Roy, Kumkum; - 'Where Women are Worshipped there the Gods Rejoice' the Mirage of the Ancestress of the Hindu Women' in Tanika Sarkar and Urvasi Bhutalia (ed) Women and Hindu Rights, Oxford University Press, New Delhi,1990.

[23]. Tambiah, S.J. 'From Varna to Caste Through Mixed Marriages' in J. Goody ed, The Character of Kinship, Cambridge University Press, Cambridge, 1973.pp 191-229. 